\title{
The Effect of Chronic Treatment with Lurasidone on Rat Liver Cytochrome P450 Expression and Activity in the Chronic Mild Stress Model of Depression
}

\author{
Marta Kot, Anna Haduch, Mariusz Papp, and Władysława A. Daniel \\ Institute of Pharmacology, Polish Academy of Sciences, Kraków, Poland
}

Received July 28, 2017; accepted September 15, 2017

\section{ABSTRACT}

Recent studies indicated an important role of the monoaminergic nervous systems (dopaminergic, noradrenergic, and serotonergic systems) and stress in the regulation of cytochrome P450 (CYP) expression and activity in the liver. The aim of our present research was to determine the effect of the novel atypical neuroleptic drug with antidepressant properties lurasidone, on the expression (mRNA and protein level) and activity of liver CYP isoforms involved in the metabolism of drugs and endogenous steroids, in the chronic mild stress (CMS) model of depression. Male Wistar rats were subjected to CMS for 7 weeks. Lurasidone ( $3 \mathrm{mg} / \mathrm{kg}$ per os per day) was administered to nonstressed or stressed animals for 5 weeks (weeks 3-7 of CMS). It has been found that 1) CMS moderately affects CYP
(CYP2B, CYP2C11, and CYP3A), and its effects are different from those observed after other kinds of psychologic stress, such as repeated restraint stress or early-life maternal deprivation; 2) chronic lurasidone influences the expression and/or activity of CYP2B, CYP2C11, and CYP3A isoforms; and 3) CMS modifies the action of lurasidone on CYP expression and function, leading to different effects of the neuroleptic in nonstressed and stressed rats. Based on the obtained results, it can be suggested that the metabolism of endogenous substrates (e.g., steroids) and drugs, catalyzed by the isoforms CYP2B, CYP2C11, or CYP3A, may proceed at a different rate in the two groups of animals (nonstressed and stressed) in the rat CMS model.

\section{Introduction}

Our earlier studies indicate an important role of the monoaminergic nervous systems (dopaminergic, noradrenergic, and serotonergic systems) in the neuroendocrine regulation of cytochrome P450 (CYP) expression in the liver, involving growth hormone, corticosterone, and thyroid hormones (Wójcikowski and Daniel, 2009; Kot and Daniel, 2011; Kot et al., 2012, 2013, 2015; Bromek et al., 2013; SadakierskaChudy et al., 2013; Rysz et al., 2015, 2016a,b; Kot and DaujatChavanieu, 2016; Kot, 2017). The above-mentioned hormones are the main physiologic regulators of $C Y P$ genes in the liver (Gibson et al., 2002; Waxman and O'Connor, 2006; Monostory et al., 2009; Dvorak and Pavek, 2010; Brtko and Dvorak, 2011; Monostory and Dvorak, 2011).

Stress, depending on its nature, intensity, and duration, produces multiple changes in the functioning of the monoaminergic systems, and thus it may affect the central neuroendocrine and autonomic regulation of liver function and CYP expression (Carrasco and Van de Kar, 2003; Uyama et al., 2004; Kot et al., 2013; Chmielarz et al., 2015). Psychotropic drugs that act on monoaminergic receptors or transporters in the brain and periphery affect the endocrine and immune systems (Jaber et al., 1994; Rane et al., 1996; Raap and Van de Kar, 1999; Drzyzga et al., 2006; Capuzzi et al., 2017; Köhler et al., 2017) and thus may also influence the liver function and CYP regulation, independently of their direct action on the monoaminergic and other receptors present

This work was supported by statutory funds from the Institute of Pharmacology, Polish Academy of Sciences.

https://doi.org/10.1124/dmd.117.077826. in the liver (Daniel, 2005; Ruddell et al., 2008; Zidek et al., 2009; Wójcikowski and Daniel, 2011; Konstandi, 2013; Kot and DaujatChavanieu, 2016).

Lurasidone is a novel atypical antipsychotic drug with a high affinity for dopamine $\mathrm{D}_{2}$, serotonin $5-\mathrm{HT}_{2 \mathrm{~A}}$, and 5- $\mathrm{HT}_{7}$ receptors. It also has antagonist activity at $\alpha_{2 \mathrm{~A}}$ and $\alpha_{2 \mathrm{C}}$ adrenergic receptors and partial agonist activity at 5- $\mathrm{HT}_{1 \mathrm{~A}}$ receptors (Ishibashi et al., 2010). It is effective in the therapy of patients with schizophrenia and shows antidepressant properties in patients with bipolar disorders (Meyer et al., 2009; Citrome, 2011; Fountoulakis et al., 2015). Lurasidone also shows antidepressant-like effects in the chronic mild stress (CMS) model of depression in the rat (Willner 1997; Luoni et al., 2014).

Lurasidone is an azapirone derivative with a benzisothiazolpiperazine side chain, metabolized predominantly by CYP3A4 in humans (Caccia, 2011; Chiu et al., 2014). The main metabolic pathways of lurasidone include oxidative $\mathrm{N}$-dealkylation between the piperazine and cyclohexane rings, hydroxylation of the norbornane ring, and S-oxidation. Other metabolic pathways comprise hydroxylation of the cyclohexane ring and reductive cleavage of the isothiazole ring, followed by S-methylation. The two major inactive metabolites are the N-dealkylation products (the acidic metabolites ID-20219 and ID-20220), and the two active metabolites are the norbornane hydroxylation products (ID-14283 and ID-14326).

In vitro study on human liver microsomes and cDNA-expressed CYP isoforms showed a modest inhibitory effect of lurasidone on the activity of CYP1A2, CYP2C19, and CYP3A4 isoforms (Wójcikowski et al., 2016; Greenberg and Citrome, 2017), but weak or no effect on other CYP enzymes, such as CYP2C9, CYP2B6, or CYP2D6. However, its possible effect on liver CYP expression produced by chronic treatment,

ABBREVIATIONS: CMS, chronic mild stress; Ct, cycle threshold; CYP, cytochrome P450; HPLC, high-pressure liquid chromatography; MD, earlylife maternal deprivation; PCR, polymerase chain reaction; $R S$, repeated restraint stress. 
which is used to treat psychiatric disorders, has not been studied as yet, although the antipsychotic or antidepressant therapy lasts for months or years.

The liver enzymatic complex of CYP is engaged in the metabolism of endogenous substrates (e.g., steroids) and drugs of different chemical structures and pharmacological groups, including psychotropics (neuroleptics, antidepressants, anxiolytics). Because comorbidity and concomitant medications are common in psychiatric patients, pharmacokinetic interactions between psychotropic drugs at a level of CYP may occur. Therefore, the aim of our present research was to investigate the effect of chronic treatment with lurasidone on the expression and activity of CYP in the rat, in normal conditions and under CMS, an animal model of depression.

\section{Materials and Methods}

Animals. Male Wistar Han rats (Charles River Laboratories, Sulzfeld, Germany), weighing 280-300 g, were singly housed with food and water freely available, and were maintained on a 12-hour light/dark cycle (lights on at 08.00 hour) under conditions of constant temperature $\left(22 \pm 2^{\circ} \mathrm{C}\right)$ and humidity $(50 \% \pm$ $5 \%$ ). All procedures used in this study were conducted in compliance with the rules and principles of the 86/609/EEC Directive, and were approved by the Bioethical Committee of the Institute of Pharmacology, Polish Academy of Sciences (Krakow, Poland).

Drugs and Chemicals. Lurasidone (hydrochloride) was provided by TargetMol (Boston, MA). NADP, NADPH, glucose-6-phosphate-dehydrogenase, glucose-6-phosphate, caffeine, and its metabolites (theobromine, paraxanthine, theophylline, and 1,3,7-trimethyluric acid) were purchased from Sigma-Aldrich (St. Louis, MO). Testosterone and its hydroxy-metabolites $(2 \alpha-, 2 \beta-, 6 \beta-, 7 \alpha-$, $16 \alpha$-, and $16 \beta$-hydroxytestosterone) were supplied by Steraloids (Newport, KY). The polyclonal rabbit primary anti-rat CYP2C11 antibody was obtained from Abcam (Cambridge, UK); the anti-rat CYP3A23/3A1 and CYP3A2 antibodies came from Millipore (Temecula, CA). The polyclonal goat anti-rat CYP2B1 antibody was form Daiichi Pure Chemicals (Tokyo, Japan). The polyclonal antirat $\beta$-actin antibody was purchased from Santa Cruz (Dallas, TX). The chemiluminescence reagents LumiGlo kit came from KPL (Gaithersburg, MD). For RNA isolation, a mirVana kit purchased from Life Technologies (Carlsbad, CA) was used. A Transcriptor High-Fidelity cDNA Synthesis Kit for reverse transcription was supplied by Roche Diagnostics (Indianapolis, IN). TaqMan assays and the TaqMan Gene Expression Master Mix were derived from Life Technologies. RNA-free water was obtained from Sigma-Aldrich. All the organic solvents of high-pressure liquid chromatography (HPLC) purity were provided by Merck (Darmstadt, Germany).

In Vivo Experiment and Liver Sample Preparation. CMS experiments were performed according to the method described previously (Papp et al., 2014). Briefly, stressed rats were subjected to the CMS procedure for a total of 7 weeks. The stress protocol consisted of the following: two periods of food or water deprivation, two periods of $45^{\circ}$ Cage tilt, two periods of intermittent illumination (lights on and off every 2 hours), two periods of soiled cage ( $250 \mathrm{ml}$ water in sawdust bedding), one period of paired housing, two periods of low-intensity stroboscopic illumination (150 flashes/min), and three periods of no stress. All stressors were 10-14 hours of duration and were applied individually and continuously, day and night. Control animals were housed in separate rooms and had no contact with the stressed animals. Following 2 weeks of initial stress, both control and stressed animals were divided into subgroups and for the next 5 weeks received once-daily per os either vehicle ( $1 \%$ hydroxyethylcellulose, $1 \mathrm{ml} / \mathrm{kg}$ ) or lurasidone $(3 \mathrm{mg} / \mathrm{kg}$ ). After 5 weeks the treatments were terminated, and 24 hours later all animals were sacrificed by decapitation and their livers were quickly removed, frozen using dry ice, and stored at $-80^{\circ} \mathrm{C}$. Microsomes were prepared from individual rat livers by differential centrifugation $(11,000 \mathrm{~g}$ and $2 \times$

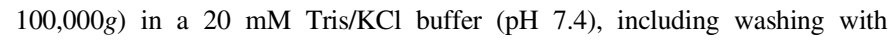
$0.15 \mathrm{M} \mathrm{KCl}$, as described previously (Kot et al., 2012). The above procedure deprives microsomes of the presence of drug administered in vivo.

Determination of CYP Isoform Activity in the Liver. The activity of CYP isoforms was studied in the livers of control rats (nonstressed and stressed) and lurasidone-treated animals (nonstressed and stressed), in the absence and presence of lurasidone added in vitro to liver microsomes. In vitro studies into isoform-specific metabolism of caffeine, warfarin, bufuralol, and testosterone in liver microsomes were carried out at the linear dependence of product formation on time, protein, and substrate concentration, in the previously optimized conditions (Daniel et al., 2006; Haduch et al., 2006; Daniel and Kot, 2008a). Incubations were conducted in a system containing the liver microsomes $(\sim 1 \mathrm{mg}$ protein/ml). The activity of CYP1A2 was determined by measuring the rate of caffeine metabolism, C-8-hydroxylation (catalyzed by CYP1A2 in the rat), and 1-N-, 3-N-, and 7-N-demethylation (catalyzed by CYP1A2 and other CYP isoforms) at a substrate concentration of $100 \mu \mathrm{M}$, as described previously (Kot and Daniel, 2008a,b), with a minor modification, i.e., the NADPH generating system was replaced with $1.5 \mathrm{mM} \mathrm{NADPH}$ (Kot et al., 2012). The final incubation volume was $1 \mathrm{ml}$, and incubation time was 50 minutes. Caffeine and its metabolites were analyzed by HPLC with UV detection (Kot and Daniel, 2008). The activity of CYP2C6 was studied by measuring the rate of warfarin 7-hydroxylation at a substrate concentration of $60 \mu \mathrm{M}$, as described previously (Daniel et al., 2006). The final incubation volume was $0.5 \mathrm{ml}$, and incubation time was 15 minutes. Warfarin and its metabolite were analyzed by HPLC with fluorescence detection. The activity of CYP2D was estimated by measuring the rate of bufuralol 1 '-hydroxylation at a substrate concentration of $10 \mu \mathrm{M}$, as described previously (Hiroi et al., 1998; Bromek et al., 2010). The final incubation volume was $0.4 \mathrm{ml}$, and incubation time was 10 minutes. Bufuralol and its metabolite were analyzed by HPLC with fluorescence detection. The activities of CYP2A, CYP2B, CYP2C11, and CYP3A were studied by measuring the rate of P450specific reactions: the $7 \alpha-, 16 \beta-, 2 \alpha-, 16 \alpha-, 2 \beta-$, and $6 \beta$-hydroxylation of testosterone, respectively, at a substrate concentration of $100 \mu \mathrm{M}$ and incubation time 15 minutes, as described previously (Haduch et al., 2006, 2008; Wójcikowski et al., 2013). The final incubation volume was $1 \mathrm{ml}$. Testosterone and its metabolites were analyzed by HPLC with UV detection. In a separate experiment, the activities of CYP2A, CYP2B, CYP2C11, and CYP3A were determined in the absence or presence of lurasidone added in vitro to pooled liver microsomes $(n=5)$ derived from nonstressed or stressed control rats, at a pharmacological/therapeutic concentration of 0.25 or $1 \mu \mathrm{M}$ (Lee et al., 2011; Chiu et al., 2014), without or with preincubation with the neuroleptic for 30 minutes. Then the substrate (testosterone) was added, and the incubation proceeded as above.

An Analysis of CYP Proteins in the Liver. The protein levels of CYP2C11, CYP2B, and CYP3A isoforms in the liver microsomes of control and lurasidonetreated rats were estimated using Western immunoblot analyses, as described previously (Kot and Daniel, 2011; Rysz et al., 2016a). Briefly, microsomal proteins (10 $\mu \mathrm{g}$ per each sample) were separated using a SDS polyacrylamide gel electrophoresis on a $12 \%$ separating gel, and then the proteins were transferred to nitrocellulose membranes (Sigma-Aldrich). The following primary antibodies for liver microsomal CYPs were used: a polyclonal rabbit anti-rat antibody raised against CYP2C11 (catalog ab3571; Lot GR33348-6; dilution 1:1150; Abcam) (Clarke et al., 2014); a polyclonal goat anti-rat antibody raised against CYP2B1, which also recognized the CYP2B2 form (Daiichi Pure Chemicals; catalog 423550; Lot C83104W; dilution 1:1600) (Zhang et al., 2000); a polyclonal rabbit anti-rat CYP3A23/3A1 (catalog AB1253; Lot 2435027; dilution 1:1600; Millipore) (Debri et al., 1995); and anti-rat CYP3A2 antibodies (catalog AB1276; Lot 242677; dilution 1:1600; Millipore) (Debri et al., 1995). After incubation with a primary antibody, the blots were incubated with a secondary antibody, e.g., an appropriate species-specific horseradish peroxidase-conjugated anti-IgG. Rat cDNA-expressed CYP2B1, CYP2C11 (5 $\mu \mathrm{g})$, CYP3A23/3A1, and CYP3A2 $(1 \mu \mathrm{g})$ isoforms (Supersomes) were used as standards. Bands on the nitrocellulose membrane were quantified with the Luminescent Image analyzer LAS-1000 using the Image Reader LAS-1000 and Image Gauge 3.11 programs (Fuji Film, Tokyo).

Isolation of Liver RNA, cDNA Synthesis, and Real-Time Analysis of the Expression of Genes Encoding CYP Isoforms. The total RNA was isolated from the frozen liver tissue using a RNeasy Plus Mini Kit (Qiagen; Hilden, Germany) following the manufacturer's instructions. The quantity and the quality of isolated RNA were verified with a NanoDrop 8000 Spectrophotometer (Thermo Scientific, Waltham, MA). RNA was stored at $-80^{\circ} \mathrm{C}$ until use. The first-strand cDNA products were generated using a Transcriptor High Fidelity cDNA Synthesis Kit (Roche Diagnostics), according to the manufacturer's instructions. Briefly, a reverse transcription was performed using $2 \mu \mathrm{g}$ total RNA and oligo(dT) primers at a total volume of $20 \mu \mathrm{l}$. cDNA synthesis was carried out at $55^{\circ} \mathrm{C}$ for 30 minutes, and at $85^{\circ} \mathrm{C}$ for 5 minutes to inactivate the 
enzyme. Following the reverse transcription, samples were diluted with $20 \mu \mathrm{l}$ RNase-free water and stored at $20^{\circ} \mathrm{C}$ until the next step of analysis. The expression of genes coding for the CYP isoform CYP2B1 (Rn01457880), CYP2B2 (Rn02786833), CYP2C11 (Rn01502203), CYP3A23/3A1 (Rn03062228), CYP3A2 (Rn00756461), and of the reference gene $\beta$-actin (Rn00667869) was detected by a real-time polymerase chain reaction (PCR) using a commercially available TaqMan Gene Expression Master Mix and species-specific TaqMan-type probes and primers (TaqMan gene expression assay; Life Technologies). The reaction mixture (10 $\mu \mathrm{l})$ consisted of $4.5 \mu \mathrm{l}$ cDNA, $5 \mu \mathrm{l}$ TaqMan Gene Expression Master Mix, and $0.5 \mu \mathrm{l}$ TaqMan assay (Life Technologies). Negative control samples were processed in a similar way, but the template was omitted. Real-time PCR runs were performed using Bio-Rad CFX96 PCR system (Bio-Rad, Hercules, CA), and standard thermal cycling conditions were used $\left(50^{\circ} \mathrm{C}\right.$ for 2 minutes, $95^{\circ} \mathrm{C}$ for 10 minutes, followed by 40 cycles of $95^{\circ} \mathrm{C}$ for 15 minutes and $60^{\circ} \mathrm{C}$ for 1 minute). The PCR of the above-mentioned target and reference genes was run in duplicate. The level of CYP transcripts was normalized to the $\beta$-actin expression, and relative quantification was obtained using the comparative $\delta-\delta$ cycle threshold $(\mathrm{Ct})$ method $\left(2^{-\Delta \Delta \mathrm{Ct}}\right)$. The relative amount of the target transcript was expressed as a fold change in the expression level relative to the calibrator (i.e., an average $\Delta \mathrm{Ct}$ of the control group).

Statistical Analysis of Data. All of the data are reported as the means $( \pm$ S.E.M.). The results were analyzed using a multivariate analysis of variance, followed by a post hoc Duncan test. The results were considered as statistically significant when $P<0.05$.

\section{Results}

The Effect of CMS and Lurasidone on the Activity of CYP Isoforms in Liver Microsomes. CMS significantly decreased the CYP2B activity measured as the testosterone $16 \beta$-hydroxylation rate and the CYP3A activity measured as the testosterone $6 \beta$-hydroxylation rate (Fig. 1), not affecting significantly the activities of other CYP isoforms tested for testosterone transformation, such as CYP2C11 (testosterone $2 \alpha$ - and $16 \alpha$-hydroxylation) and CYP2A (testosterone $7 \alpha$-hydroxylation). The rate of caffeine metabolism representing the CYP1A2 activity (C-8-hydroxylation and N-demethylations) (Fig. 2), the rate of warfarin 7-hydroxylation corresponding to the CYP2C6 activity, and the rate of bufuralol 1'-hydroxylation indicative of the CYP2D activity (Fig. 3) also remained unchanged. Lurasidone significantly increased the CYP2B and CYP3A activity in stressed rats, but decreased the CYP2C11 activity in both nonstressed and stressed animals (Fig. 1). The activities of other CYP isoforms studied (CYP2A, CYP1A2, CYP2C6, and CYP2D) were not significantly affected by lurasidone (Figs. 1-3).

The Effect of CMS and Lurasidone on the Protein Level of CYP Isoforms in Liver Microsomes. Searching for molecular mechanisms of the observed changes in the activities of CYP isoforms after CMS and/or lurasidone, the level of CYP protein was studied in liver microsomes. CMS significantly decreased the CYP2C11 and CYP3A2 protein level, but increased that of CYP3A23/3A1 (Fig. 4, A and B). Lurasidone significantly diminished the CYP2B protein level in nonstressed rats, but tended to enhance it in stressed animals. The CYP2B protein level after lurasidone treatment was significantly higher in stressed than nonstressed subjects. The CYP2C11 protein level was significantly reduced by lurasidone, but only in nonstressed animals. The neuroleptic significantly increased the CYP3A23/3A1 protein level (but not that of CYP3A2) in both nonstressed and stressed rats (Fig. 4, A and B). Consequently, the CYP3A1 protein level in lurasidone-treated rats was much higher in stressed than nonstressed animals.

The Effect of CMS and Lurasidone on the mRNA Level of CYP Isoforms in Liver Tissue. Searching further for genetic mechanisms of the observed changes in CYP isoform activities and protein levels, the effect of CMS and/or lurasidone on the mRNA level of $C Y P$ genes was investigated in liver tissue. CMS did not produce any significant changes in the mRNA levels of the tested genes $C Y P 2 B 1, C Y P 2 B 2, C Y P 2 C 11$, $C Y P 3 A 23 / 3 A 1$, and $C Y P 3 A 2$, although a tendency toward increased mRNA level of $C Y P 2 B 1$ and $C Y P 2 B 2$ genes was noted (Fig. 5). Lurasidone significantly increased the $C Y P 3 A 23 / 3 A 1$ and $C Y P 3 A 2$ mRNA level in both nonstressed and stressed rats. The neuroleptic raised the $C Y P 2 B 1$ mRNA level in nonstressed rats, but tended to decrease it in stressed animals (Fig. 5). The $C Y P 2 B 1$ mRNA level after
A

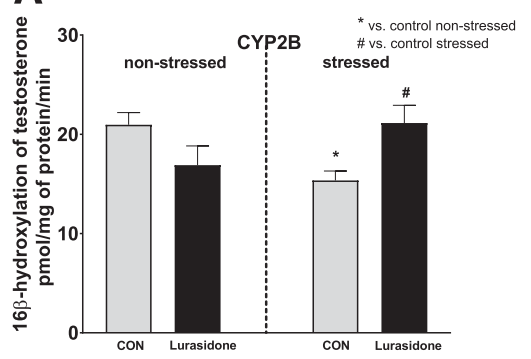

D

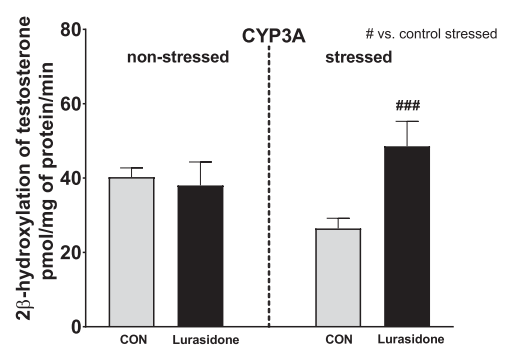

B

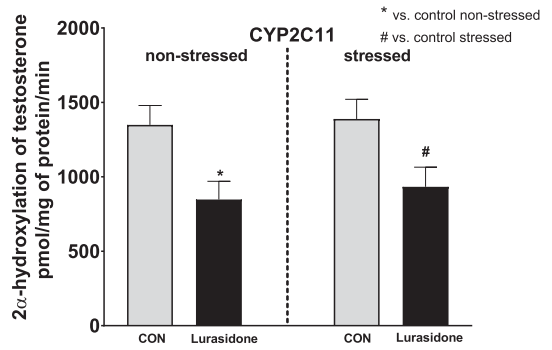

E

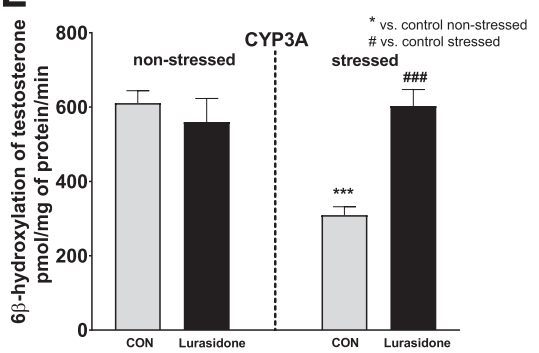

C

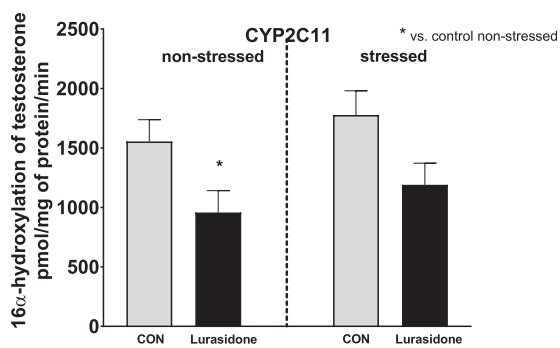

F

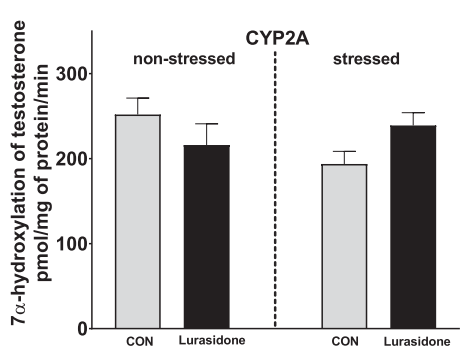

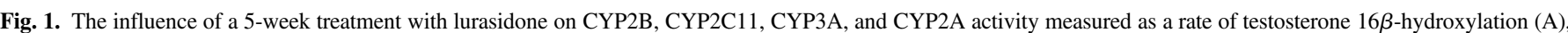

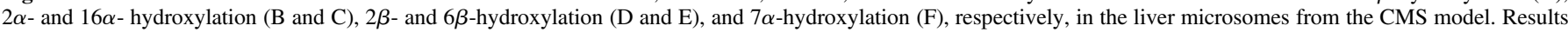

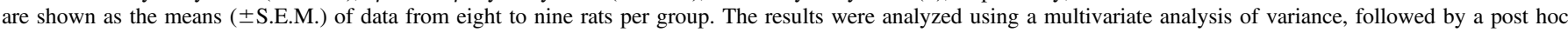

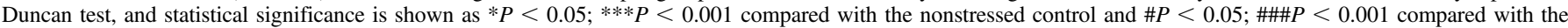
stressed control. CON, control. 
A

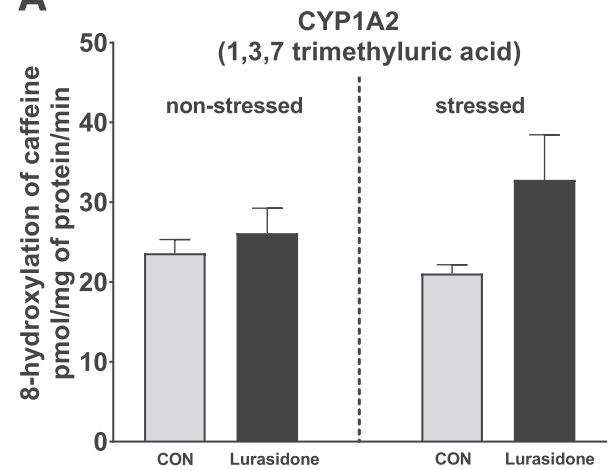

C

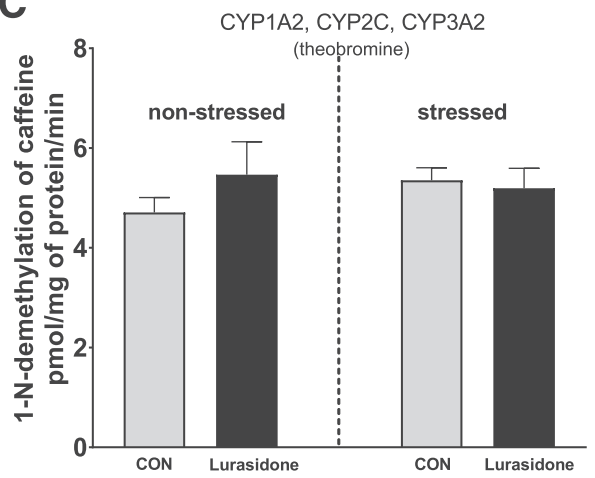

B

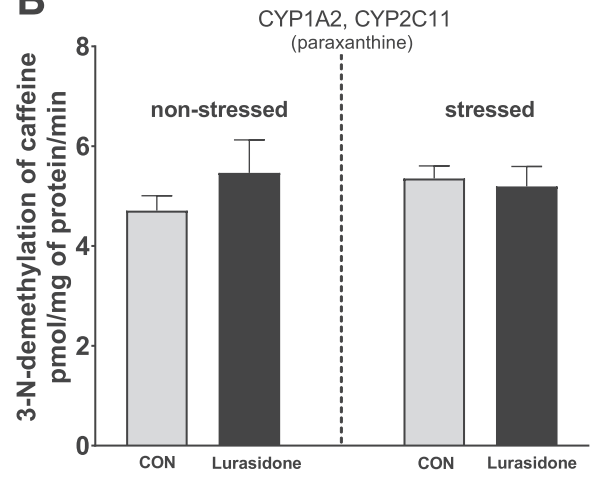

D

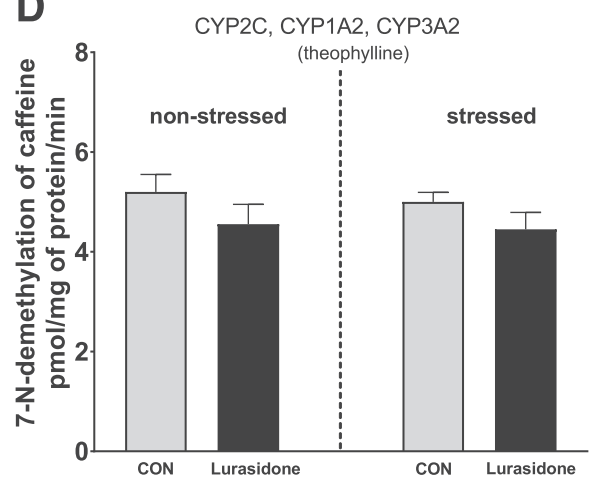

Fig. 2. The influence of a 5-week treatment with lurasidone on CYP1A2 activity measured as a rate of caffeine metabolism in the liver microsomes from the CMS model. (A) C-8hydroxylation, catalyzed by CYP1A2; (B) 3-Ndemethylation, catalyzed by CYP1A2 and CYP2C11; (C) 1-N-demethylation, catalyzed by CYP1A2, CYP2C, and CYP3A2; (D) 7-Ndemethylation, catalyzed by CYP2C, CYP1A2, and CYP3A2. Results are shown as the means $( \pm$ S.E.M.) of data from nine rats per group. The results were analyzed using a multivariate analysis of variance, followed by a post hoc Duncan test. CON, control. lurasidone treatment was significantly lower in stressed than nonstressed subjects. Lurasidone did not significantly affect the mRNA levels of the genes $C Y P 2 B 2$ or $C Y P 2 C 11$.

The Effect of Lurasidone Added In Vitro to the Control Liver Microsomes of Nonstressed and Stressed Rats on the Activity of CYP Isoforms Measured as the Rate of Testosterone Metabolism. Lurasidone added to liver microsomes of nonstressed control rats at a concentration of $0.25 \mu \mathrm{M}$ did not affect significantly the testosterone $2 \beta$ - and $6 \beta$-hydroxylation rate, representing the CYP3A activity. However, at the higher concentration of $1 \mu \mathrm{M}$, the neuroleptic moderately decreased the CYP3A activity (Fig. 6). After preincubation of the liver microsomes with lurasidone for 30 minutes, the effect of the neuroleptic on the enzyme activity was seen also at its lower concentration of $0.25 \mu \mathrm{M}$. Similar effects were observed in the liver microsomes derived from stressed control animals; however, in this case the effect of lurasidone on the CYP3A activity was less pronounced, i.e., preincubation with $0.25 \mu \mathrm{M}$ lurasidone was not effective in the inhibition of testosterone $2 \beta$-hydroxylation. Moreover, weak or moderate inhibitory effects of 0.25 and $1 \mu \mathrm{M}$ lurasidone on the CYP2A activity (the rate of $7 \alpha$-hydroxylation of testosterone) and $1 \mu \mathrm{M}$ lurasidone on the CYP2B activity (the rate of $16 \beta$-hydroxylation of testosterone) were observed. The metabolic reactions of testosterone representing the CYP2C11 activity ( $2 \alpha$ - and $16 \alpha$-hydroxylation) were least affected and only by the higher $(1 \mu \mathrm{M})$ concentration of lurasidone.

\section{Discussion}

The obtained results show significant effects of CMS and chronic lurasidone treatment on CYP expression and activity. They indicate that lurasidone differently influences CYP in nonstressed and stressed animals (summarized in Table 1).

CMS, an animal model of depression, significantly decreased the CYP2B activity and tended to do so to the CYP2B protein, but it produced an opposite effect on mRNA level, i.e., a tendency to increase the $C Y P 2 B 1$ and $C Y P 2 B 2$ mRNA level was observed. The CYP2C11 protein level was decreased by CMS, without a change in the enzyme
A

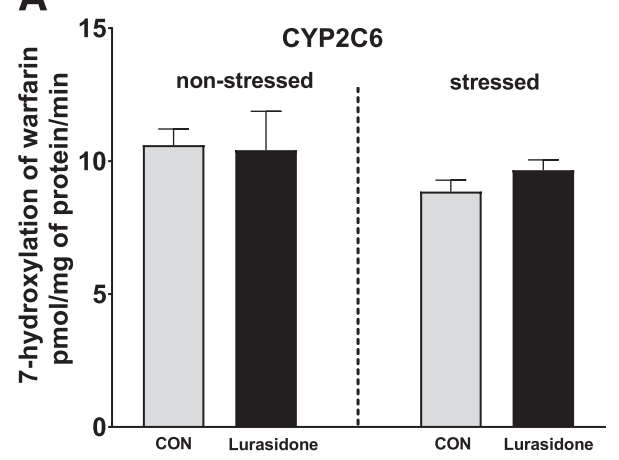

B

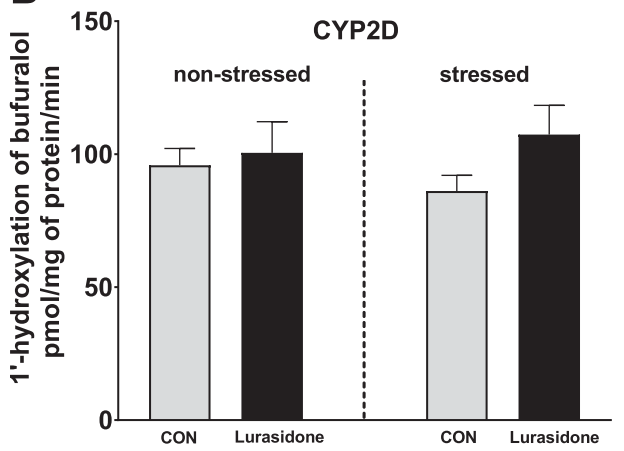

Fig. 3. The influence of a 5-week treatment with lurasidone on CYP2C6 and CYP2D activity measured as a rate of warfarin 7-hydroxylation (A) and bufuralol 1'-hydroxylation (B), respectively, in the liver microsomes from the CMS model. Results are shown as the means ( \pm S.E.M. $)$ of data from nine rats per group. The results were analyzed using a multivariate analysis of variance, followed by a post hoc Duncan test. CON, control. 


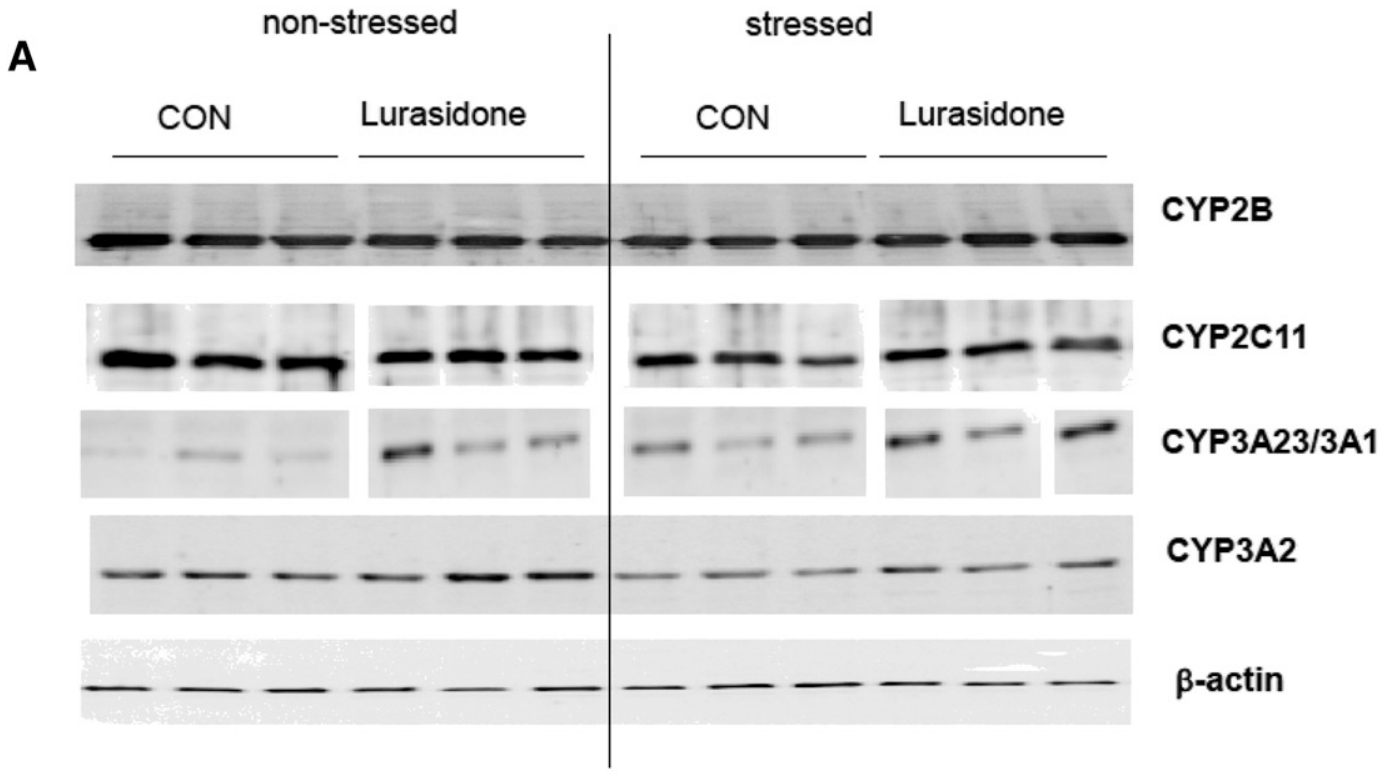

B

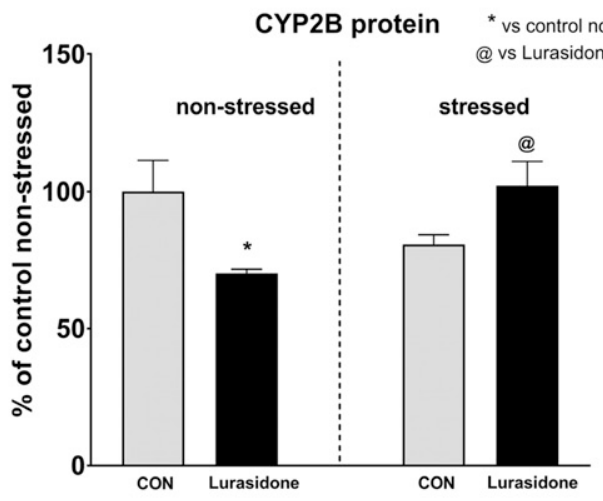

D

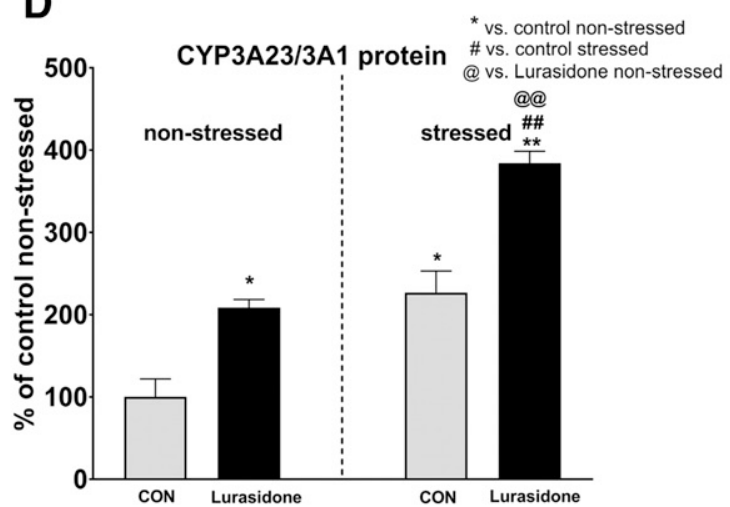

C

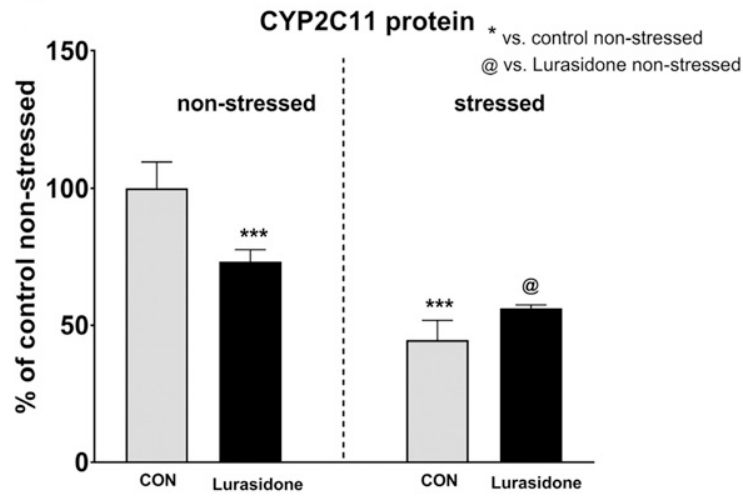

$E$

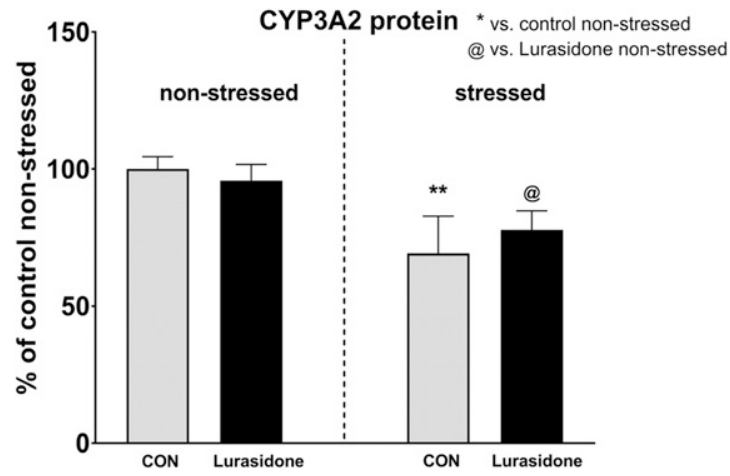

Fig. 4. The effect of a 5-week treatment with lurasidone on the protein level of CYP2B, CYP2C11, CYP3A1, and CYP3A2 in rat liver microsomes from the CMS model. (A) Microsomal proteins, $10 \mu \mathrm{g}$, were subjected to the Western immunoblot analysis. Rat cDNA-expressed CYP2B1, CYP2C11, CYP3A1, and CYP3A2 isoforms (Supersomes) were used as standards. The original membranes of CYP2C11 and CYP3A23/3A1 were cut down to arrange protein bands according to the order of experimental groups presented in Fig. 4B. (B-D) Results are shown as the means ( \pm S.E.M.) of data from six to eight rats per group. The results were analyzed using a multivariate analysis of variance, followed by a post hoc Duncan test, and statistical significance is shown as $* P<0.05 ; * * P<0.01 ; * * * P<0.001$ compared with the nonstressed control and \#\#P<0.01 compared with the stressed control or @P $<0.05$; @ @P $<0.01$ compared with lurasidone nonstressed. CON, control.

activity or mRNA level. In the case of the CYP3A subfamily, its activity and the protein level of CYP3A2 were decreased by CMS (at an increased CYP3A1 protein), but no change in the mRNA level of the two CYP3A23/3A1 and CYP3A2 isoforms was noted. The observed noncorresponding changes in the activity, protein, and mRNA levels of the investigated CYP isoforms suggest some posttranscriptional or posttranslational modifications in CYP expression produced by CMS in the liver. The observed changes in CYP expression and activity may be caused by the ability of CMS to produce alterations in the function of the brain nervous system (Willner, 2016), which leads to the release of glucocorticoids and catecholamines, and modifications in the immune system (Kvetnansky et al., 2009; Jiang et al., 2014; Konstandi et al., 
A
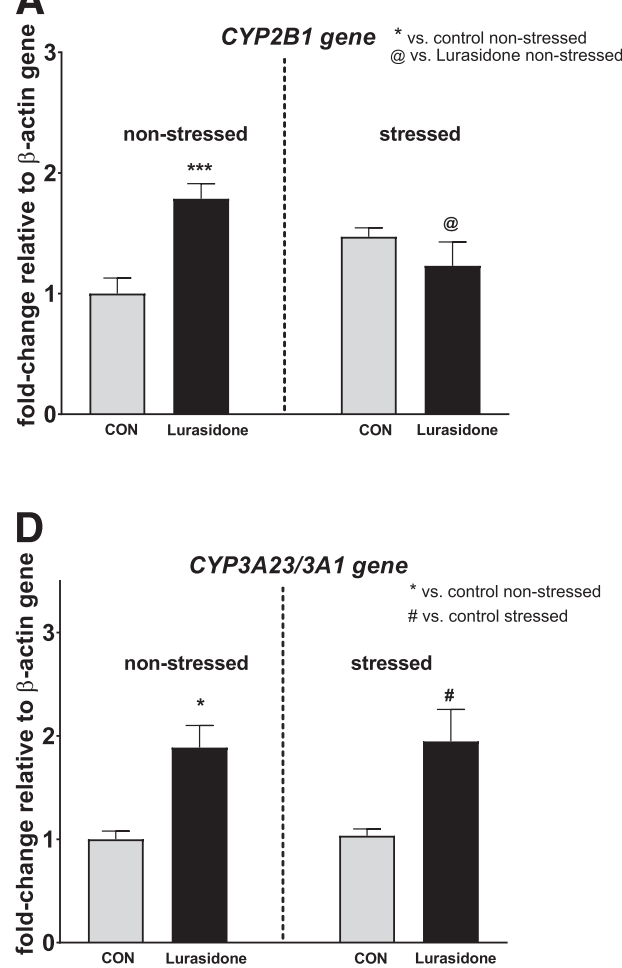
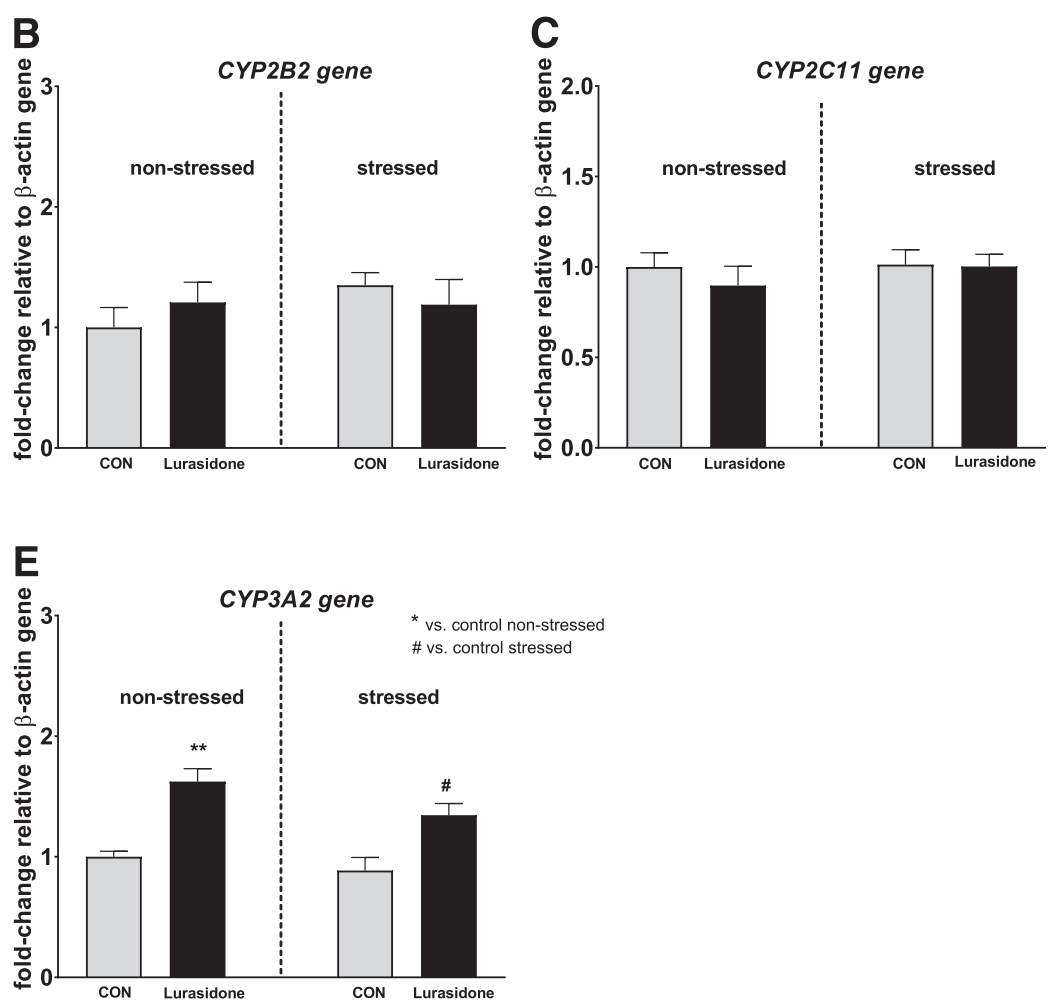

Fig. 5. The effect of a 5-week treatment with lurasidone on the mRNA expression level of CYP2B1, CYP2B2, CYP2C11, CYP3A1, and CYP3A2 genes (A, B, C, D, and E, respectively) in the liver microsomes from the CMS model. Results are shown as the means ( \pm S.E.M.) of data from 7 to 10 rats/group. The results were analyzed using a multivariate analysis of variance, followed by a post hoc Duncan test, and statistical significance is shown as $* P<0.05 ; * * P<0.01 ; * * * P<0.001$ compared with the nonstressed control and \#P<0.05 compared with the stressed control or @P $<0.05$ compared with lurasidone nonstressed. CON, control.

2014; Tank and Lee Wong, 2015; Faron-Górecka et al., 2016; Rossetti et al., 2016). The aforementioned CMS-evoked physiopathologic changes in the concentrations of peripheral glucocorticoids, catecholamines, and cytokines affect hepatic signaling pathways mediating the regulation of CYP (Konstandi, 2013). Glucocorticoids are known to have complex (direct and/or indirect), mostly positive effects on the expression/activity of rat hepatic CYP2B (Waxman et al., 1990), CYP2C11 (Iber et al., 1997), and CYP3A (Huss and Kasper, 2000). However, these effects may be modified by catecholamines (adrenaline, noradrenaline) acting positively via hepatocyte $\alpha_{1}$ and $\beta_{1 / 2}$ adrenergic receptor through the cAMP response element-binding protein pathway, but negatively via pancreatic $\beta_{2}$ receptor through the insulin pathway (Konstandi, 2013) on CYP expression (Konstandi, 2013). Moreover, CMS-induced immune disturbances that lead to elevation of plasma proinflammatory cytokines (interleukin- 6 , tumor necrosis factor- $\alpha$, and tumor necrosis factor- $\gamma$ ) may additionally diminish enzyme expression (Zidek et al., 2009; Jiang et al., 2014).

The obtained results indicate that the effect of CMS on liver CYP is rather moderate and differs from the effects of other kinds of stress observed in rodents, such as repeated restraint stress (RS) or early-life maternal deprivation (MD) (Daskalopoulos et al., 2012b). As compared with CMS, the CYP3A2 expression was increased both in RS and MD rats, which was not the case in the CMS-exposed animals in our experiment. The expression of liver CYP2C11 and CYP3A1 was increased in MD, but not in RS rats, whereas in the CMS animals a decrease and an increase of those CYP isoforms, respectively, were observed. In contrast, the CYP2D activity was increased in RS, but not in MD or CMS subjects. In contrast, the CYP2B activity in RS rats was significantly suppressed (Konstandi et al., 2000) like in CMS animals in our study. The above-described stress-dependent differences in CYP expression and function support an earlier assumption that the effect of psychologic stress on CYP is stress type specific. The specificity of stress seems to be determined by the proportion of engagement of the brain stress circuits and peripheral nervous systems and, in consequence, the contribution of the neuroendocrine and sympathetic nervous systems to the regulation of liver CYP expression (Uyama et al., 2004; Kot et al., 2013; Chmielarz at al., 2015; Tank and Lee Wong, 2015).

Chronic lurasidone, which exerts antidepressant action in the CMS model of depression (Luoni et al., 2014), has been shown to be active in the regulation of the expression of some CYP isoforms in our experiment. Notably, its effect was different in nonstressed and stressed animals, in particular in the case of the CYP2B subfamily (summarized in Table 1). Lurasidone produced an opposite effect on $C Y P 2 B 1 \mathrm{mRNA}$, CYP2B protein, and activity in nonstressed rats (an increase, a decrease, and a tendency to decrease, respectively) and stressed animals (a tendency to decrease, a tendency to increase, and an increase, respectively). Moreover, lurasidone decreased the activity of CYP2C11, the main CYP isoform in male rats, both in nonstressed and stressed rats, although it decreased the enzyme protein only in nonstressed animals, not affecting the levels of $C Y P 2 C 11 \mathrm{mRNA}$ in both groups of rats (nonstressed and stressed). As concerns the CYP3A subfamily, the neuroleptic affected its expression in both nonstressed and stressed rats in a similar manner (an increase in $C Y P 3 A 23 / 3 A 1 \mathrm{mRNA}$ and protein and in CYP3A2 mRNA); however, the CYP3A activity was enhanced only in stressed animals.

The observed difference in the CYP3A activity between the two groups of rats (nonstressed and stressed) after lurasidone treatment may be caused by different concentrations of reactive lurasidone metabolites, a greater amount of which may be formed in nonstressed than stressed animals. This is because the results of our experiment show that CMS 

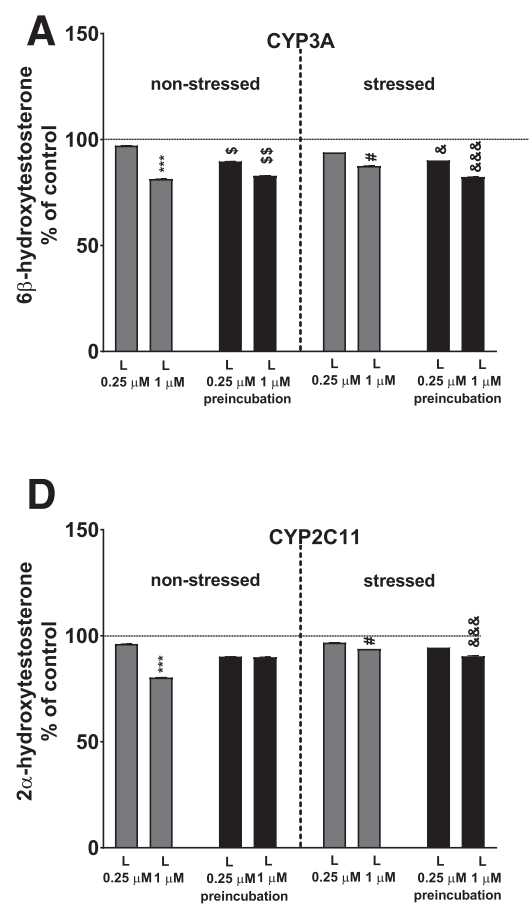

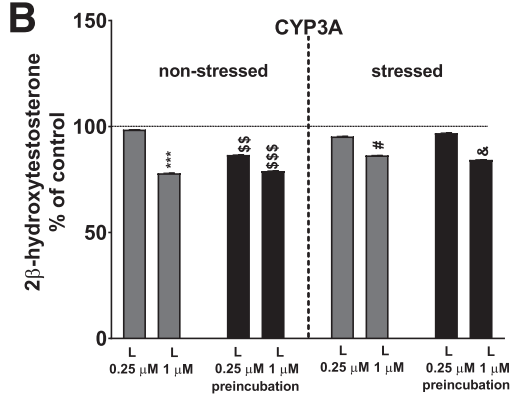

E

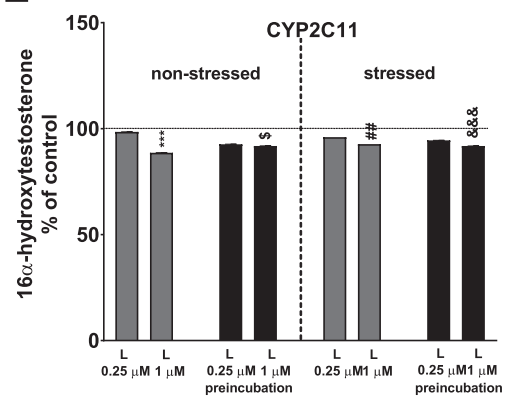

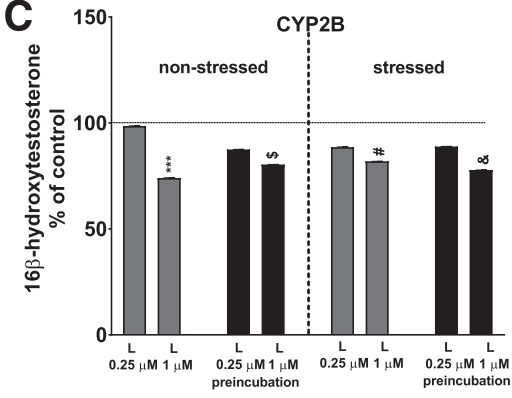

$\mathbf{F}$

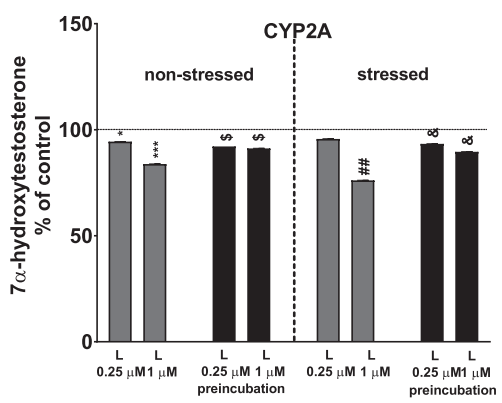

\& vs. control stressed with preincubation

Fig. 6. The effect of lurasidone added in vitro to pooled liver microsomes of nonstressed and stressed (CMS) rats on the activity of CYP3A, CYP2B, CYP2C11, and CYP2A, measured as the rate of testosterone $2 \beta$ - and $6 \beta$-hydroxylation (A and B), $16 \beta$-hydroxylation (C), $2 \alpha$ - and $16 \alpha$-hydroxylation (D and E), and $7 \alpha$-hydroxylation (F), respectively. All values are the mean \pm S.E.M. $(n=5)$. The results were analyzed statistically using a multivariate analysis of variance, followed by a post hoc Duncan test. Statistical significance is shown as $* P<0.05 ; * * * P<0.001$ compared with the nonstressed control and $\# P<0.05$; \#\#P<0.01 compared with the stressed control (withouot preincubation) or $\$ P<0.05 ; \$ \$ P<0.01 ; \$ \$ P<0.001$ compared with the nonstressed control and $\& P<0.05 ; \& \& \& P<0.001$ compared with the stressed control (with preincubation). The control values (picomoles per milligram protein per minute) for liver microsomes of nonstressed rats are as follows: without preincubation:

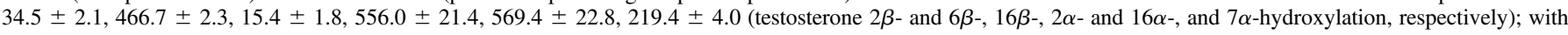
incubation: $34.3 \pm 1.2,346.0 \pm 10.4,11.2 \pm 0.7,463.3 \pm 19.0,511.5 \pm 11.3,180.2 \pm 6.1$ (testosterone $2 \beta$ - and $6 \beta-, 16 \beta$-, $2 \alpha-$ and $16 \alpha-$, and $7 \alpha$-hydroxylation, respectively). The control values (picomoles per milligram protein per minute) for liver microsomes of stressed (CMS) rats are as follows: without preincubation: $25.7 \pm 0.5$, $298.7 \pm 2.9,14.9 \pm 0.3,842.1 \pm 11.5,938.5 \pm 9.1,187.3 \pm 2.3$ (testosterone $2 \beta$ - and $6 \beta-, 16 \beta-, 2 \alpha$ - and $16 \alpha$-, and $7 \alpha$-hydroxylation, respectively); with incubation: $26.1 \pm 0.03,231.0 \pm 2.7,10.8 \pm 0.1,738.7 \pm 6.7,826.9 \pm 0.8,171.1 \pm 3.3$ (testosterone $2 \beta$ - and $6 \beta-, 16 \beta-, 2 \alpha$ - and $16 \alpha-$, and $7 \alpha$-hydroxylation, respectively). L, lurasidone.

decreases the activity of CYP3A, i.e., the enzyme primarily responsible for the lurasidone metabolism (Caccia, 2011). As mentioned elsewhere, lurasidone is extensively metabolized in vivo via N-dealkylation, hydroxylation, and S-oxidation, and reactive metabolites possibly generated during this process may inactivate the CYP3A protein and, in turn, mask the functional effect of increased enzyme expression by the neuroleptic in nonstressed animals. This kind of phenomenon was observed earlier for phenothiazine neuroleptics, tricyclic antidepressants, and selective serotonin reuptake inhibitors, in vitro and in vivo (Murray and Field, 1992; Bensoussan et al., 1995; Murray and Murray, 2003; Daniel et al., 2005; Haduch et al., 2006). This suggestion finds some support in the results of our in vitro study showing that lurasidone added to control liver microsomes is more efficient in nonstressed rats than in CMS animals in the inhibition of CYP3A activity measured as the testosterone $2 \beta$-hydroxylation rate.

Finally, it should be mentioned that the observed effects of lurasidone on CYP may be connected with the pharmacological action of the neuroleptic, in particular with its antagonist activity at dopaminergic $\mathrm{D}_{2}$, serotonergic 5- $\mathrm{HT}_{2}$, and adrenergic $\alpha_{2}$ receptors in the brain and/or periphery, which affects the central (Wójcikowski and Daniel, 2009; Sadakierska-Chudy et al., 2013; Rysz et al., 2015; Daniel et al., 2017) and peripheral (Daskalopoulos et al., 2012a; Kot

TABLE 1

Summary of the effects of CMS and/or lurasidone on the activity, protein, and mRNA levels of liver CYP isoforms

$\uparrow, \downarrow$ Increase or decrease, respectively; $(\uparrow),(\downarrow)$ a tendency to increase or decrease, respectively.

\begin{tabular}{|c|c|c|c|c|c|c|c|c|c|c|}
\hline & & CYP1A2 & CYP2A & CYP2B1 & CYP2B2 & CYP2C6 & CYP2C11 & CYP2D & CYP3A1 & CYP3A2 \\
\hline \multirow[t]{3}{*}{ CMS } & Activity & No change & $(\downarrow)$ & \multirow{2}{*}{\multicolumn{2}{|c|}{$\underset{(\downarrow)}{\downarrow}$}} & \multirow[t]{3}{*}{ No change } & No change & \multirow[t]{3}{*}{ no change } & \multicolumn{2}{|c|}{$\downarrow$} \\
\hline & Protein & & & & & & & & $\uparrow$ & $\downarrow$ \\
\hline & mRNA & & & $(\uparrow)$ & $(\uparrow)$ & & No change & & No change & No change \\
\hline \multirow{3}{*}{$\begin{array}{l}\text { Lurasidone } \\
\text { (vs. nonstressed control) }\end{array}$} & Activity & No change & No change & & $(\downarrow)$ & No change & $\downarrow$ & No change & \multicolumn{2}{|c|}{ No change } \\
\hline & Protein & & & & $\downarrow$ & & $\downarrow$ & & $\uparrow$ & No change \\
\hline & mRNA & & & $\uparrow$ & No change & & No change & & $\uparrow$ & $\uparrow$ \\
\hline \multirow{3}{*}{$\begin{array}{l}\text { CMS + Lurasidone } \\
\text { (vs. stressed control) }\end{array}$} & Activity & \multirow[t]{3}{*}{$(\uparrow)$} & \multirow[t]{3}{*}{ No change } & & $\uparrow$ & \multirow[t]{3}{*}{ No change } & $\downarrow$ & No change & \multicolumn{2}{|c|}{$\uparrow$} \\
\hline & Protein & & & & $(\uparrow)$ & & No change & & $\uparrow$ & No change \\
\hline & mRNA & & & $(\downarrow)$ & No change & & No change & & $\uparrow$ & $\uparrow$ \\
\hline
\end{tabular}


and Daujat-Chavanieu, 2016; Kot, 2017) endocrine regulation of liver CYP, and hepatic signaling pathways mediating enzyme expression. CMS affects the brain monoaminergic neurotransmission (Willner, 2016), which may modify the action of lurasidone on the regulation of some CYP isoforms in stressed animals. Combinations of atypical neuroleptics and antidepressants or antiepileptics are frequently used by clinicians, which may lead to pharmacodynamic and/or pharmacokinetic interactions (Kennedy et al., 2013; Spina and de Leon, 2014). Chronic lurasidone was found to modestly increase plasma concentration of the specific CYP3A4 substrate midazolam in patients with schizophrenia or schizoaffective disorders (Chiu et al., 2014). However, its possible effects on the pharmacokinetics of antidepressant drugs that are metabolized by CYP3A isoforms have been investigated neither in volunteers and depressive patients nor in an animal model of depression, as yet.

In summary, the present findings indicate that 1) CMS moderately affects CYP (CYP2B, CYP2C11, and CYP3A), and its effects are different from those observed after other kinds of psychologic stress, such as repeated RS or early-life MD; 2) chronic lurasidone influences the expression and/or activity of CYP2B, CYP2C11, and CYP3A isoforms; and 3) CMS modifies the action of lurasidone on CYP expression and function, leading to the different effects of the neuroleptic in nonstressed and stressed rats. Future studies will focus on testing whether the metabolism of endogenous substrates (e.g., steroids) and drugs, catalyzed by the isoforms CYP2B, CYP2C11, or CYP3A, proceeds at a different rate in the two groups of animals (nonstressed and stressed) in the rat CMS model.

\section{Authorship Contributions}

Participated in research design: Daniel, Papp.

Conducted experiments: Kot (biochemical study), Papp, Haduch (in vivo study).

Performed data analysis: Kot, Daniel.

Wrote or contributed to the writing of the manuscript: Daniel, Kot, Papp.

\section{References}

Bensoussan C, Delaforge M, and Mansuy D (1995) Particular ability of cytochromes P450 3A to form inhibitory P450-iron-metabolite complexes upon metabolic oxidation of aminodrugs. Biochem Pharmacol 49:591-602.

Bromek E, Haduch A, and Daniel WA (2010) The ability of cytochrome P450 2D isoforms to synthesize dopamine in the brain: an in vitro study. Eur J Pharmacol 626:171-178.

Bromek E, Wójcikowski J, and Daniel WA (2013) Involvement of the paraventricular (PVN) and arcuate (ARC) nuclei of the hypothalamus in the central noradrenergic regulation of liver cytochrome P450. Biochem Pharmacol 86:1614-1620.

Brtko J and Dvorak Z (2011) Role of retinoids, rexinoids and thyroid hormone in the expression of cytochrome p450 enzymes. Curr Drug Metab 12:71-88.

Caccia S (2011) Pharmacokinetics and metabolism update for some recent antipsychotics. Expert Opin Drug Metab Toxicol 7:829-846.

Capuzzi E, Bartoli F, Crocamo C, Clerici M, and Carrà G (2017) Acute variations of cytokine levels after antipsychotic treatment in drug-naive subjects with a first-episode psychosis: a metaanalysis. Neurosci Biobehav Rev 77:122-128.

Carrasco GA and Van de Kar LD (2003) Neuroendocrine pharmacology of stress. Eur J Pharmacol 463:235-272.

Chiu YY, Ereshefsky L, Preskorn SH, Poola N, and Loebel A (2014) Lurasidone drug-drug interaction studies: a comprehensive review. Drug Metabol Drug Interact 29:191-202.

Chmielarz P, Kreiner G, Kot M, Zelek-Molik A, Kowalska M, Bagińska M, Daniel WA, and Nalepa I (2015) Disruption of glucocorticoid receptors in the noradrenergic system leads to BDNF up-regulation and altered serotonergic transmission associated with a depressive-like phenotype in female GR(DBHCre) mice. Pharmacol Biochem Behav 137:69-77.

Citrome L (2011) Lurasidone for schizophrenia: a review of the efficacy and safety profile for this newly approved second-generation antipsychotic. Int J Clin Pract 65:189-210.

Clarke JD, Hardwick RN, Lake AD, Canet MJ, and Cherrington NJ (2014) Experimental nonalcoholic steatohepatitis increases exposure to simvastatin hydroxy acid by decreasing hepatic organic anion transporting polypeptide expression. J Pharmacol Exp Ther 348:452-458.

Daniel WA (2005) The influence of long-term treatment with psychotropic drugs on cytochrome P450: the involvement of different mechanisms. Expert Opin Drug Metab Toxicol 1:203-217.

Daniel WA, Haduch A, Bromek E, Rysz M, and Wójcikowski J (2017) Activation of hypothalamic 5-HT1 and 5-HT2 receptors differently regulates endocrine responses and liver cytochrome P450 expression and activity, in 6th Mediterranean Neuroscience Society Conference; 2017 June 12-15; Malta, Xjenza. pp. 200-201. Malta Chamber of Scientists, Valletta, Malta.

Daniel WA, Haduch A, Syrek M, and Boksa J (2006) Direct and indirect interactions between antidepressant drugs and CYP2C6 in the rat liver during long-term treatment. Eur Neuropsychopharmacol 16:580-587.
Daniel WA, Haduch A, and Wójcikowski J (2005) Inhibition of rat liver CYP2D in vitro and after 1-day and long-term exposure to neuroleptics in vivo: possible involvement of different mechanisms. Eur Neuropsychopharmacol 15:103-110.

Daskalopoulos EP, Lang MA, Marselos M, Malliou F, and Konstandi M (2012a) $\mathrm{D}_{2}$-dopaminergic receptor-linked pathways: critical regulators of CYP3A, CYP2C, and CYP2D. Mol Pharmacol 82:668-678

Daskalopoulos EP, Malliou F, Rentesi G, Marselos M, Lang MA, and Konstandi M (2012b) Stres is a critical player in CYP3A, CYP2C, and CYP2D regulation: role of adrenergic receptor signaling pathways. Am J Physiol Endocrinol Metab 303:E40-E54.

Debri K, Boobis AR, Davies DS, and Edwards RJ (1995) Distribution and induction of CYP3A1 and CYP3A2 in rat liver and extrahepatic tissues. Biochem Pharmacol 50:2047-2056.

Drzyzga L, Obuchowicz E, Marcinowska A, and Herman ZS (2006) Cytokines in schizophrenia and the effects of antipsychotic drugs. Brain Behav Immun 20:532-545.

Dvorak Z and Pavek P (2010) Regulation of drug-metabolizing cytochrome P450 enzymes by glucocorticoids. Drug Metab Rev 42:621-635.

Faron-Górecka A, Kuśmider M, Kolasa M, Żurawek D, Szafran-Pilch K, Gruca P, Pabian P, Solich J, Papp M, and Dziedzicka-Wasylewska M (2016) Chronic mild stress alters the somatostatin receptors in the rat brain. Psychopharmacology (Berl) 233:255-266.

Fountoulakis KN, Gazouli M, Kelsoe J, and Akiskal H (2015) The pharmacodynamic properties of lurasidone and their role in its antidepressant efficacy in bipolar disorder. Eur Neuropsychopharmacol 25:335-342.

Gibson GG, Plant NJ, Swales KE, Ayrton A, and El-Sankary W (2002) Receptor-dependent transcriptional activation of cytochrome P4503A genes: induction mechanisms, species differences and interindividual variation in man. Xenobiotica 32:165-206.

Greenberg WM and Citrome L (2017) Pharmacokinetics and pharmacodynamics of lurasidone hydrochloride, a second-generation antipsychotic: a systematic review of the published literature. Clin Pharmacokinet 56:493-503.

Haduch A, Wójcikowski J, and Daniel WA (2006) The effect of tricyclic antidepressants, selective serotonin reuptake inhibitors (SSRIs) and newer antidepressant drugs on the activity and level of rat CYP3A. Eur Neuropsychopharmacol 16:178-186.

Haduch A, Wójcikowski J, and Daniel WA (2008) Effect of selected antidepressant drugs on cytochrome P450 2B (CYP2B) in rat liver: an in vitro and in vivo study. Pharmacol Rep 60 957-965.

Hiroi T, Imaoka S, and Funae Y (1998) Dopamine formation from tyramine by CYP2D6. Biochem Biophys Res Commun 249:838-843.

Huss JM and Kasper CB (2000) Two-stage glucocorticoid induction of CYP3A23 through both the glucocorticoid and pregnane X receptors. Mol Pharmacol 58:48-57.

Iber H, Chen Q, Sewer M, and Morgan ET (1997) Regulation of hepatic cytochrome P450 2C11 by glucocorticoids. Arch Biochem Biophys 345:305-310.

Ishibashi T, Horisawa T, Tokuda K, Ishiyama T, Ogasa M, Tagashira R, Matsumoto K, Nishikawa H, Ueda Y, Toma S, et al. (2010) Pharmacological profile of lurasidone, a novel antipsychotic agent with potent 5-hydroxytryptamine 7 (5-HT7) and 5-HT1A receptor activity. $J$ Pharmacol Exp Ther 334:171-181.

Jaber M, Tison F, Fournier MC, and Bloch B (1994) Differential influence of haloperidol and sulpiride on dopamine receptors and peptide mRNA levels in the rat striatum and pituitary. Brain Res Mol Brain Res 23:14-20.

Jiang P, Zhang L, Zhu W, Li H, Dang R, and Tang M (2014) Chronic stress causes neuroendocrine-immune disturbances without affecting renal vitamin D metabolism in rats. $J$ Endocrinol Invest 37:1109-1116.

Kennedy WK, Jann MW, and Kutscher EC (2013) Clinically significant drug interactions with atypical antipsychotics. CNS Drugs 27:1021-1048.

Konstandi M (2013) Psychophysiological stress: a significant parameter in drug pharmacokinetics. Expert Opin Drug Metab Toxicol 9:1317-1334.

Konstandi M, Johnson E, Lang MA, Camus-Radon AM, and Marselos M (2000) Stress modulates the enzymatic inducibility by benzo[alpha]pyrene in the rat liver. Pharmacol Res 42:205-211.

Konstandi M, Johnson EO, and Lang MA (2014) Consequences of psychophysiological stress on cytochrome P450-catalyzed drug metabolism. Neurosci Biobehav Rev 45:149-167.

Kot M (2017) Hormonal context in the regulation of cytochrome P450 (CYP) during liver insufficiency with serotonergic system dysfunction. Drug Metab Pharmacokinet 32 (Suppl): S39-S40.

Kot M and Daniel WA (2008a) Relative contribution of rat cytochrome P450 isoforms to the metabolism of caffeine: the pathway and concentration dependence. Biochem Pharmacol 75 : $1538-1549$.

Kot M and Daniel WA (2008b) Caffeine as a marker substrate for testing cytochrome P450 activity in human and rat. Pharmacol Rep 60:789-797.

Kot M and Daniel WA (2011) Cytochrome P450 is regulated by noradrenergic and serotonergic systems. Pharmacol Res 64:371-380.

Kot M and Daujat-Chavanieu M (2016) The impact of serotonergic system dysfunction on the regulation of $\mathrm{P} 4501 \mathrm{~A}$ isoforms during liver insufficiency and consequences for thyroid hormone homeostasis. Food Chem Toxicol 97:70-81.

Kot M, Kreiner G, Chmielarz P, Kuśmierczyk J, Nalepa I, and Daniel WA (2013) Genderdependent activity of CYP3A is indirectly modified by GR in the noradrenergic system. Pharmacol Rep 65:1431-1434.

Kot M, Pilc A, and Daniel WA (2012) Simultaneous alterations of brain and plasma serotonin concentrations and liver cytochrome P450 in rats fed on a tryptophan-free diet. Pharmacol Res 66:292-299.

Kot M, Sadakierska-Chudy A, Haduch A, Rysz M, Bromek E, Gołembiowska K, and Daniel WA (2015) The role of the dorsal noradrenergic pathway of the brain (locus coeruleus) in the regulation of liver cytochrome P450 activity. Eur J Pharmacol 751:34-41.

Köhler CA, Freitas TH, Stubbs B, Maes M, Solmi M, Veronese N, de Andrade NQ, Morris G, Fernandes BS, Brunoni AR, et al. (2017) Peripheral alterations in cytokine and chemokine levels after antidepressant drug treatment for major depressive disorder: systematic review and metaanalysis. Mol Neurobiol DOI: 10.1007/s12035-017-0632-1 [published ahead of print]

Kvetnansky R, Sabban EL, and Palkovits M (2009) Catecholaminergic systems in stress: structural and molecular genetic approaches. Physiol Rev 89:535-606.

Lee KR, Chae YJ, and Koo TS (2011) Pharmacokinetics of lurasidone, a novel atypical antipsychotic drug, in rats. Xenobiotica 41:1100-1107.

Luoni A, Macchi F, Papp M, Molteni R, and Riva MA (2015) Lurasidone exerts antidepressant properties in the chronic mild stress model through the regulation of synaptic and neuroplastic mechanisms in the rat prefrontal cortex. Int J Neuropsychopharmacol 18:1-12. 
Meyer JM, Loebel AD, and Schweizer E (2009) Lurasidone: a new drug in development for schizophrenia. Expert Opin Investig Drugs 18:1715-1726.

Monostory K and Dvorak Z (2011) Steroid regulation of drug-metabolizing cytochromes P450. Curr Drug Metab 12:154-172.

Monostory K, Pascussi JM, Kóbori L, and Dvorak Z (2009) Hormonal regulation of CYP1A expression. Drug Metab Rev 41:547-572.

Murray M and Field SL (1992) Inhibition and metabolite complexation of rat hepatic microsomal cytochrome P450 by tricyclic antidepressants. Biochem Pharmacol 43:2065-2071.

Murray M and Murray K (2003) Mechanism-based inhibition of CYP activities in rat liver by fluoxetine and structurally similar alkylamines. Xenobiotica 33:973-987.

Papp M, Gruca P, Lasoń-Tyburkiewicz M, Adham N, Kiss B, and Gyertyán I (2014) Attenuation of anhedonia by cariprazine in the chronic mild stress model of depression. Behav Pharmacol $\mathbf{2 5}$ 567-574.

Raap DK and Van de Kar LD (1999) Selective serotonin reuptake inhibitors and neuroendocrine function. Life Sci 65:1217-1235.

Rane A, Liu Z, Levol R, Bjelfman C, Thyr C, Ericson H, Hansson T, Henderson C, and Wolf CR (1996) Differential effects of neuroleptic agents on hepatic cytochrome P-450 isozymes in the male rat. Biochim Biophys Acta 1291:60-66.

Rossetti AC, Papp M, Gruca P, Paladini MS, Racagni G, Riva MA, and Molteni R (2016) Stressinduced anhedonia is associated with the activation of the inflammatory system in the rat brain: restorative effect of pharmacological intervention. Pharmacol Res 103:1-12.

Ruddell RG, Mann DA, and Ramm GA (2008) The function of serotonin within the liver. J Hepatol 48:666-675.

Rysz M, Bromek E, and Daniel WA (2016a) Activation of brain serotonergic system by repeated intracerebral administration of 5-hydroxytryptophan (5-HTP) decreases the expression and activity of liver cytochrome P450. Biochem Pharmacol 99:113-122.

Rysz M, Bromek E, Haduch A, Liskova B, Wójcikowski J, and Daniel WA (2016b) The reverse role of the hypothalamic paraventricular (PVN) and arcuate (ARC) nuclei in the central serotonergic regulation of the liver cytochrome P450 isoform CYP2C11. Biochem Pharmacol 112:82-89.

Rysz M, Bromek E, Haduch A, Sadakierska-Chudy A, and Daniel WA (2015) Damage to the brain serotonergic system increases the expression of liver cytochrome P450. Drug Metab Dispos 43:1345-1352.

Sadakierska-Chudy A, Haduch A, Rysz M, Gołembiowska K, and Daniel WA (2013) The role of brain noradrenergic system in the regulation of liver cytochrome P450 expression. Biochem Pharmacol 86:800-807.

Spina E and de Leon J (2014) Clinically relevant interactions between newer antidepressants and second-generation antipsychotics. Expert Opin Drug Metab Toxicol 10:721-746.
Tank AW and Lee Wong D (2015) Peripheral and central effects of circulating catecholamines. Compr Physiol 5:1-15.

Uyama N, Geerts A, and Reynaert H (2004) Neural connections between the hypothalamus and the liver. Anat Rec A Discov Mol Cell Evol Biol 280:808-820.

Waxman DJ, Morrissey JJ, Naik S, and Jauregui HO (1990) Phenobarbital induction of cytochromes P-450: high-level long-term responsiveness of primary rat hepatocyte cultures to drug induction, and glucocorticoid dependence of the phenobarbital response. Biochem 271:113-119.

Waxman DJ and O'Connor C (2006) Growth hormone regulation of sex-dependent liver gene expression. Mol Endocrinol 20:2613-2629.

Willner P (1997) Validity, reliability and utility of the chronic mild stress model of depression: a 10-year review and evaluation. Psychopharmacology (Berl) 134:319-329.

Willner P (2016) The chronic mild stress (CMS) model of depression: history, evaluation and usage. Neurobiol Stress 6:78-93.

Wójcikowski J, Basińska-Ziobroń A, Danek P, and Daniel WA (2016) The effect of the nove atypical atipsychotic drug lurasidone on cytochrome P450 isoenzyme activities in human liver, in 2nd Central European Biomedical Congress: From Emerging Biochemical Strategies to Personalized Medicine; 2016 June 15-18; Kraków, Poland. pp. 102. Jagiellonian University Medical College and Polish Academy of Sciences Institute of Pharmacology, Kraków, Poland.

Wójcikowski J and Daniel WA (2009) The brain dopaminergic system as an important center regulating liver cytochrome P450 in the rat. Expert Opin Drug Metab Toxicol 5:631-645.

Wójcikowski J and Daniel WA (2011) The role of the nervous system in the regulation of liver cytochrome p450. Curr Drug Metab 12:124-138.

Wójcikowski J, Haduch A, and Daniel WA (2013) Effect of antidepressant drugs on cytochrome P450 2C11 (CYP2C11) in rat liver. Pharmacol Rep 65:1247-1255.

Zhang L, Weddle DL, Thomas PE, Zheng B, Castonguay A, Schuller HM, and Miller MS (2000) Low levels of expression of cytochromes P-450 in normal and cancerous fetal pancreatic tissues of hamsters treated with NNK and/or ethanol. Toxicol Sci 56:313-323.

Zídek Z, Anzenbacher P, and Kmonícková E (2009) Current status and challenges of cytokine pharmacology. Br J Pharmacol 157:342-361.

Address correspondence to: Dr. Władysława A. Daniel, Institute of Pharmacology, Polish Academy of Sciences, Smętna 12, 31-343 Kraków, Poland. E-mail: nfdaniel@cyf-kr.edu.pl 